\title{
TEXTILE-REINFORCED CONCRETE STRUCTURAL ELEMENTS
}

\author{
Dan Alexandru LIBOTEAN ${ }^{1}$, Alexandru CHIRA ${ }^{2}$, Ferdinánd-Zsongor GOBESZ ${ }^{3}$ \\ Technical University of Cluj-Napoca, Faculty of Civil Engineering, Department of \\ Structural Mechanics, Cluj-Napoca, Romania \\ ${ }^{1}$ liboteandanalexandru@yahoo.com \\ 2 alexandru.chira@mecon.utcluj.ro \\ 3go@mecon.utcluj.ro
}

\begin{abstract}
The textile reinforced concrete is a material with increased mechanical properties that can allow the production of lighter structural elements. The alkali-resistant textile reinforcement is not affected by corrosion. A structural facade panel and a light pole were modeled in order to study their behavior in the case of wind pressure. The developed numerical simulations were calibrated according to available data from the literature. These simulations revealed information potentially useful in the planning of further experimental tests.
\end{abstract}

Keywords: textile reinforced concrete, alkali-resistant glass-fibres, finite element method, numerical simulations.

\section{Introduction}

The development of high performance concrete (HPC) and ultra-high performance concrete (UHPC) has led the necessity for a new technology that can allow a sustainable evolution for the reinforced concrete industry. In recent years an increased interest from architects and engineers has emerged regarding the use of innovative and performant materials which allowed a continuous evolution for the composite materials. The traditional way of using steel reinforcement is by imposing a minimum cover thickness of $5 \mathrm{~cm}$ for structural elements because of corrosion and fire codes. The combination of textile reinforcement (glass, basalt, carbon alkali resisting fibres with a polymeric matrix) with high performance concrete allows the production of structural elements with a 10 times lower thickness and with improved mechanical properties compared to traditional ones. Regarding sustainability, the use of textile reinforced concrete (TRC) can be favorable because of material reduction and low environmental footprint. Numerous studies have been carried out in this field, with respect to structural functionality, durability, production, application and design.

The concrete used for TRC is usually based on fine grained concrete with aggregates that do not exceed $2 \mathrm{~mm}$. Besides the increase in concrete strength, (for TRC the HPC and UHPC type of concrete is used) the reduced granulation allows a better impregnation of the concrete in the textile reinforcement grid [1]. The reinforcement of the TRC elements generally involves 2D or $3 \mathrm{D}$ meshes whose fibres are made of 
alkali-resistant glass (ARG), carbon, basalt, polypropylene, polyvinyl-alcohol (PVAc) with a polyvinyl chloride (PVC) matrix or a hybrid mixture of these materials [2]. TRC is a composite material with a diverse application in such fields as: structural retrofitting [3-7], lightweight structures [8, 9] or facade panels [10-14]. Depending on the desired geometry, the TRC elements are obtained using different methods: forming, spraying or rolling [15].

The objective of this study is to collect information on the behavior of some structural elements of the TRCs dominated by wind action (in our case facade panels and lighting poles). A number of simulations were carried out to meet the proposed objective, using the commercial Abaqus finite element software [16]. These studies are at the same time an initial step before the experimental tests that will follow.

\section{Materials and methods}

\subsection{Materials}

For the textile reinforcement, the 2D glass fibre reinforcement grid is used, as illustrated in Figure 1. Its fibres consist of 1500-2000 yarns coated with a polymeric epoxy resin matrix. The binding type is chain, the mesh sizes being $10 \times 25 \mathrm{~mm}$. The area of the fibre section is $3.80 \mathrm{~mm}^{2}$ and for the calculations, the modulus of elasticity was considered as $33250 \mathrm{MPa}$ and the tensile strength $475 \mathrm{MPa}$.

More types of concrete were considered for the numerical simulations, so besides the classical common classes C25/30 and C20/25, the models were made considering the characteristics of the following types of TRC:

- TRC106 / C106 (compression strength: $106 \mathrm{MPa}, \mathrm{E}=49 \mathrm{GPa}$ );

- TRC90 (compression strength: $90 \mathrm{MPa}$, $\mathrm{E}=40 \mathrm{GPa})$;

- TRC70 (compression strength: $70 \mathrm{MPa}, \mathrm{E}$ $=35 \mathrm{GPa})$.

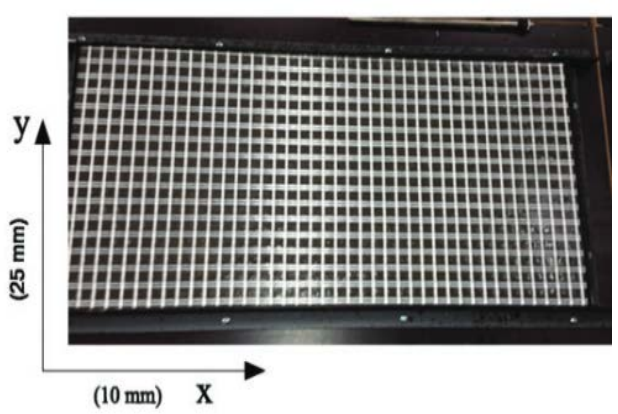

Figure 1.,2D AR-Glass” textile reinforcement [11].

\subsection{Structural elements}

Panels of $25 \times 300 \times 700 \mathrm{~mm}$ have been modeled in terms of bearing and loading as illustrated in Figure 2. (separately for each of the five types of concrete, considering a $6 \mathrm{~mm}$ concrete cover on the reinforcement). This mode of loading corresponds to the experimental testing that will be carried out in the future.

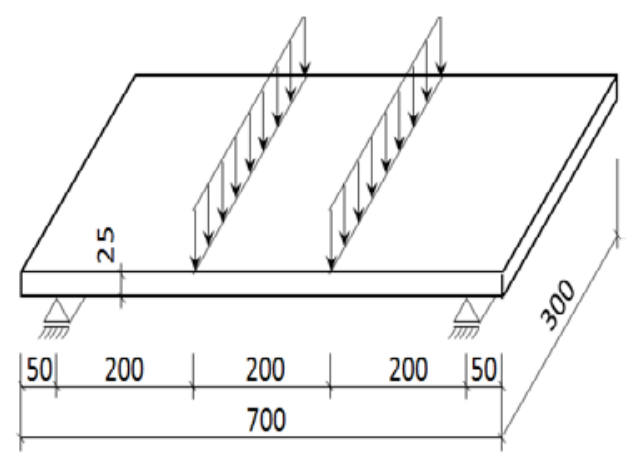

Figure 2. Facade panel model, lying down (the dimensions are in $\mathrm{mm}$ ).

The $260 \times 260 \times 4550 \mathrm{~mm}$ lighting poles were modelled with $10 \times 10 \mathrm{~mm}$ textile reinforcement grid (with the same mechanical features as the "2D AR-Glass" mesh). In the tube section, the 2D grid was positioned in the middle of every pole side. Unlike the facade panels, only three cases were considered here: TRC106 (aka C106 with rein- 
forcement), C106 (without reinforcement) and common C20/25 also without reinforcement. The loading was considered uniformly distributed on one of the sides of the pole as shown in Figure 3.

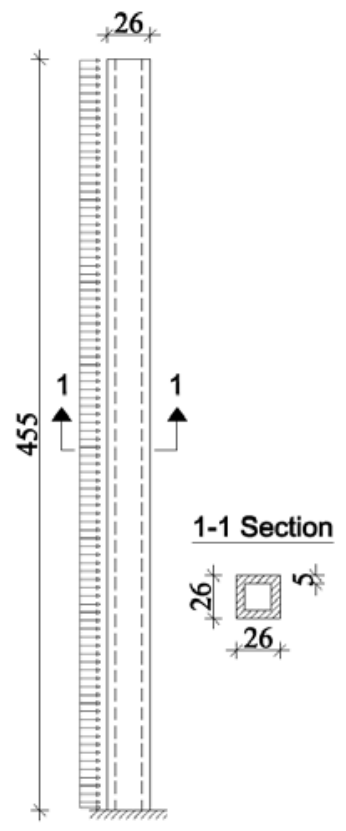

Figure 3. Lighting pole model (dimensions in $\mathrm{cm}$ ).

\subsection{Numerical simulations}

Beam elements with 2 nodes (T3D2) were used for the reinforcement modeling and solid brick elements with 8 nodes (C3D8R) for the concrete. For both textile reinforcement and concrete a mesh of $8 \mathrm{~mm}$ was used in the FEM, considering a perfect bond between the reinforcement and the concrete. The material constitutive law for concrete was modelled based on CDM (Concrete Damage Plasticity) and a Plasticity material law was assumed for the textile reinforcement. Thus, in both cases the material nonlinearity was taken into account.

Considering the concrete properties as variables, 5 numerical simulations were carried out for the facade panels and 3 for the lighting poles. A static Riks nonlinear analysis (that uses an incremental loading increase until loss of strength or stability) was employed for all these simulations.

\section{Results and discussion}

\subsection{Facade panels}

The results of numerical simulations are presented in graphical form for both types of structural elements. For the facade panels it is observed that in the case of concrete classes with a lower compressive strength the first plastic deformations appear at lower forces, but the strength reserves are similar to those in the upper concrete classes (Figure 4).

In Figures 5. and 6. the development of plastic areas for the compressed and stretched zones respectively can be observed.

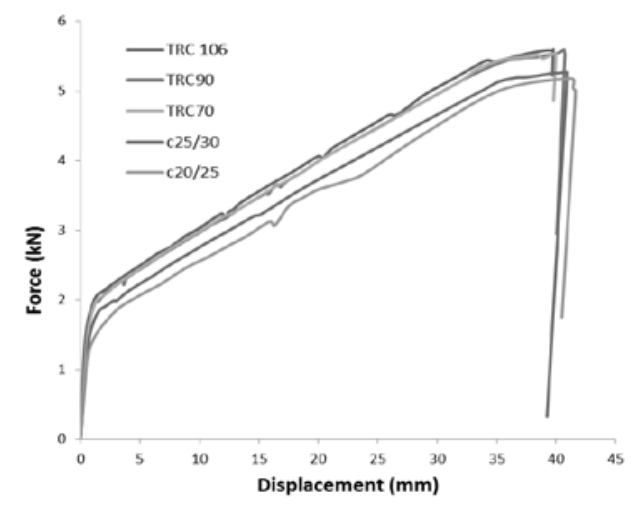

Figure 4. Force-displacement by facade panels (the markings of the material models follow the order of the curves).

The lower classes of concrete have been introduced for comparison in order to try a more cost-effective approach regarding the facade panels. Although it is possible to use lower concrete classes for the TRC panels, due to the technological requirements (the use of fine grained concrete is needed in order to obtain an efficient penetration of 
the concrete in the textile reinforcement grid), the concrete recipe will be included in a higher class in terms of compressive strengths [17].

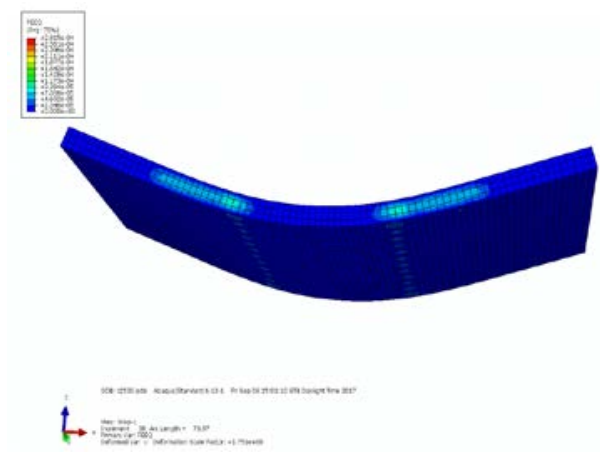

Figure 5. Typical compression plastic strains.

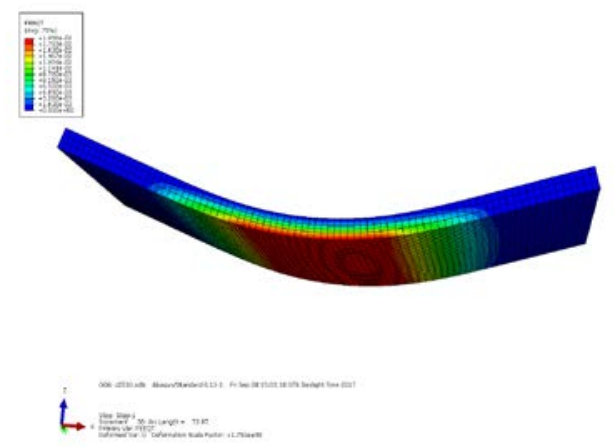

Figure 6. Typical tensile plastic strains.

\subsection{Lighting poles}

The lighting poles were considered fixed at the ground level (all degrees of freedom were blocked). A uniform pressure load was applied on one side of the poles in order to simulate the wind action.

From Figure 7. it can be observed that the influence of the textile reinforcement is relatively small. The reinforcement becomes effective with the formation of the first plastic areas (base of the column), so the role of this reinforcement is strictly to obtain additional strength reserves.

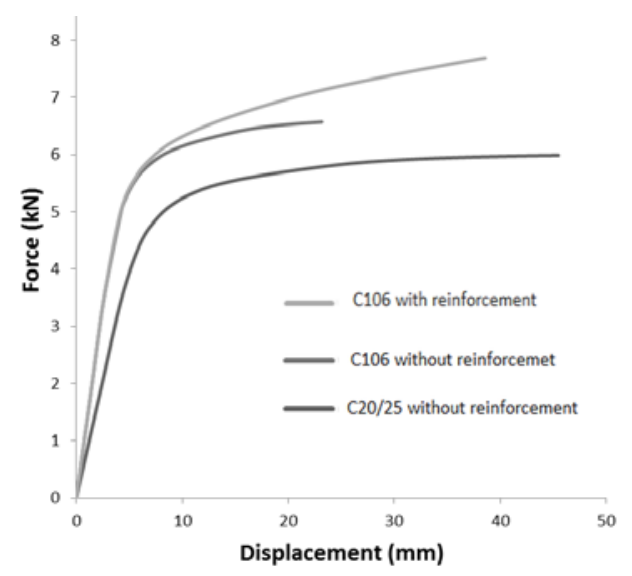

Figure 7. Force-displacement by lighting poles (the markings of the material models follow the order of the curves).

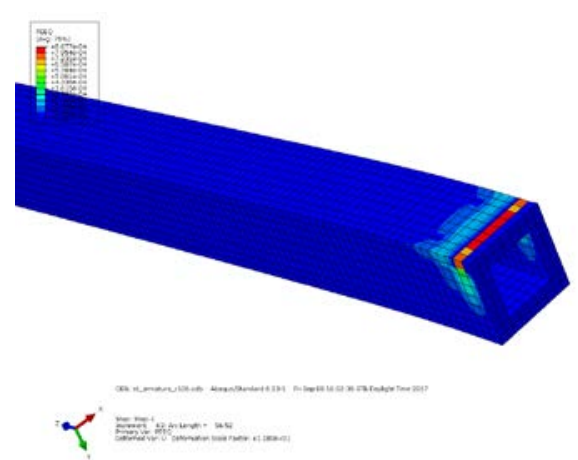

Figure 8. Compression plastic strain (column base plasticizing).

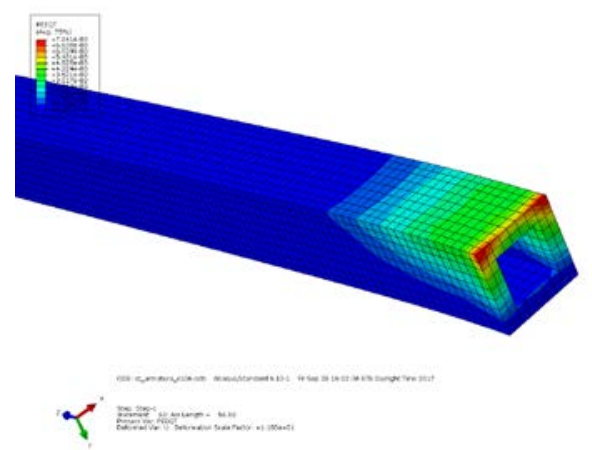

Figure 9. Tensile plastic strain (column base plasticizing). 


\section{Conclusions}

One of the purposes of the numerical evaluations was to obtain preliminary data for subsequent experimental tests (such as optimizing the number of experiments and to predict the behavior of the proposed elements from the results given by the numerical simulations that take into account all sources of nonlinearity).

Due to the technological conditions it is not possible to use aggregates having a grain size over $4 \mathrm{~mm}$ in TRC elements, which leads to higher classes of concrete. In order to obtain lightweight structural elements it is necessary to use corrosion resistant reinforcements (like alkali treated textile reinforcement), thus the use of conventional steel reinforcement is excluded.

Following the employed numerical simulations, the following were found:

- The use of lower concrete classes with textile reinforcement for facade panels leads to small differences in stiffness and strength;

- In the case of both the panels and the proposed lighting poles, the use of highstrength concrete leads to an increase in the strength value (approximately $40 \%$ for TRC panels, approximately $15 \%$ for TRC lighting poles);

- The textile reinforcement has the role of providing sufficient strength reserves so that we have an announced collapse of the proposed structural elements.

An important objective is also the extent to which sustainability criteria are fulfilled (reducing the amount of the required materials and of the input energy, while increasing the service life), and, economic considerations. Using TRC is not necessarily cheaper, but could prove to be more effective.

\section{References}

[1] State-of-the-Art report of RILEM Technical Committee TC 201-TRC 'Textile Reinforced
Concrete'. In: RILEM report 36. (ed.: Brameshuber W.), Bagneux, France, 2006.

[2] Williams Portal N.: Usability of Textile Reinforced Concrete: Structural Performance, Durability and Sustainability. PhD thesis, Chalmers University of Technology, Göteborg, Sweden, 2015.

http://publications.lib.chalmers.se/records/full text/220895/220895.pdf

[3] Contamine R., Si Larbi A., Hamelin P.: Identifying the contributing mechanisms of textile reinforced concrete (TRC) in the case of shear repairing damaged and reinforced concrete beams. Engineering Structures, 46/1. (2013) 447-458.

https://doi.org/10.1016/j.engstruct.2012.07.024

[4]Brückner A., Ortlepp R., Curbach M.: Anchoring of shear strengthening for T-beams made of textile reinforced concrete (TRC). Materials and Structures, 41/2. (2008) Springer, 2008, pp. 407-418. https://doi.org/10.1617/s11527-007-9254-9

[5]Papanicolaou C. G., Triantafillou Th. C., Papathanasiou M., Karlos K.: Textile reinforced mortar (TRM) versus FRP as strengthening material of URM walls: out-ofplane cyclic loading. Materials and Structures, vol. 41/1. (2008) 143-157. https://doi.org/10.1617/s11527-007-9226-0

[6]Bernat-Maso E., Gil L., Roca P.: Numerical analysis of the load-bearing capacity of brick masonry walls strengthened with textile reinforced mortar and subjected to eccentric compressive loading. Engineering Structures, 91. (2015) 96-111.

https://doi.org/10.1016/j.engstruct.2015.02.032

[7] Verbruggen S., Aggelis D. G., Tysmans T., Wastiels J.: Bending of beams externally reinforced with TRC and CFRP monitored by DIC and AE. Composite Structures, 112. (2014) 113-121.

https://doi.org/10.1016/j.compstruct.2014.02. 006

[8]Hegger J., Kulas Ch., Horstmann M.: Spatial textile reinforcement structures for ventilated and sandwich façade elements. Advances in Structural Engineering, 15/4. (2012) 665-675. https://doi.org/10.1260/1369-4332.15.4.665

[9]_Schneider H. N., Schätzke Ch., Feger Ch., Horstmann M., Pak D.: Modulare Bausysteme aus Textilbeton- sandwichelementen, Textilbeton - Theorie und Praxis: Tagungs- 
band zum 4. Kolloquium zu textilbewehrten Tragwerken (CTRS4) und zur 1. Anwendertagung, T. U. Dresden, Germany, 2009, 565576.

[10] Chira A., Kumar A., Vlach T., Laiblová L., Škapin A. S., Hájek P.: Property improvements of alkali resistant glass fibres/epoxy composite with nanosilica for textile reinforced concrete applications. Materials \& Design, 89. (2016) 146-155. https://doi.org/10.1016/j.matdes.2015.09.122

[11] Chira A., Kumar A., Vlach T., Laiblová L., Hajek P.: Textile-reinforced concrete facade panels with rigid foam core prisms. Journal of Sandwich Structures \& Materials, 18/2. (2016) 200-214.

https://doi.org/10.1177/1099636215613488

[12] Gopinath S, Kumar V. R., Sheth H., Murthy A. R., Iyer N. R.: Pre-fabricated sandwich panels using cold-formed steel and textile reinforced concrete. Construction and Building Materials, 64. (2014), 54-59.

https://doi.org/10.1016/j.conbuildmat.2014.0 4.068
[13] Shams A., Hegger J., Horstmann M.: An analytical model for sandwich panels made of textile-reinforced concrete. Construction and Building Materials, 64. (2014) 451-459. https://doi.org/10.1016/j.conbuildmat.2014.0 4.025

[14] Dey V., Zani G., Colombo M., Di Prisco M., Mobasher B.: Flexural impact response of textile-reinforced aerated concrete sandwich panels. Materials \& Design, 86/12. (2015) 187-197. https://doi.org/10.1016/j.matdes.2015.07.004

[15] Hegger J., Voss S.: Investigations on the bearing behaviour and application potential of textile reinforced concrete. Engineering Structures, 30/7. (2008) 2050-2056. https://doi.org/10.1016/j.engstruct.2008.01.006

[16] ABAQUS, Finite element software, Hibbitt, Karlsson \& Sorensen Inc., USA.

[17] Kausay T.: Beton. A betonszabvány néhány fejezetének értelmezése, Mérnöki Kamara Nonprofit Kft, Budapest, Hungary, 2013. 